\title{
Free flexural vibration studies on laminated composite skew plates
}

\author{
C.V. Srinivasa ${ }^{1, *}$, Y.J. Suresh ${ }^{2}$, W.P. Prema Kumar ${ }^{3}$ \\ 1, * Department of Mechanical Engineering, GM Institute of Technology, Davangere, Karnataka, INDIA-577006 \\ ${ }^{2}$ Departments of Mechanical Engineering, J.N.N. College of Engineering, Shivamogga, Karnataka, INDIA-577204 \\ ${ }^{3}$ Departments of Civil Engineering, Nagarjuna College of Engineering \& Technology, Bangalore-562110, INDIA \\ "Corresponding Author: e-mail:srinivas@gmit.info, Tel +91-8192-233345/77, Fax. +91-8192-233344
}

\begin{abstract}
This paper presents studies made on fundamental flexural frequencies of isotropic and laminated composite skew plates with simply supported and clamped boundary conditions. The fundamental flexural frequencies have been obtained using finite element, the accuracy of which is verified against literature values. The effects of the skew angle, aspect ratio and length-tothickness-ratio on the fundamental frequency of isotropic skew plates are presented. In addition, the effect of parameters such as skew angle, fiber orientation angle, numbers of layers in the laminate and laminate sequence on the fundamental frequencies of antisymmetric composite laminates have also been presented. It is found that the CQUAD8 element yields better results than the CQUAD4 element in the said study of free flexural vibration. The frequencies are found to increase with the skew angle. When the number of layers in the laminate is large, the variation of frequency with the number of layers is not appreciable.
\end{abstract}

Keywords: Skew Plates, Antisymmetric Laminates, Free Flexural Vibration, Fundamental Frequency Coefficient, Frequency Ratio.

DOI: http://dx.doi.org/10.4314/ijest.v4i4.2

\section{Introduction}

The skew plates find a wide range of application in civil, marine, aeronautical and mechanical engineering applications. They are often used in modern structures in spite of the mathematical difficulties involved in their study. The various applications of skew plates can be found in swept wings of aeroplanes, complex alignment problems in bridge design, ship hulls and parallelogram slabs in buildings. The exact solutions to skew plate vibration problems are rare, and those available in the literature are based on approximate methods. Over the past four decades, a lot of research has been carried out on the study of vibration characteristics of skew plates. Today the skew plate problem has been widely used by FEM as a benchmark check on the capability of a particular newly developed finite element.

The earlier studies on free vibration characteristics of skew plates are those of Barton (1951), Kaul and Cadambe (1956) and Hasegawa (1957), using Rayleigh-Ritz method. Hamada (1959) applied the Lagrangian-multiplier method to obtain the fundamental frequency of the rhombic skew plate. Claassen (1963) extended the work of Barton (1951) by adopting a Fourier sine series solution scheme in conjunction with the Rayleigh-Ritz method. Conway and Farnham (1965) employed the point matching method to study the free vibration of triangular, rhombic and parallelogram plates. The frequencies were calculated for different skew angles of simply supported and clamped boundary conditions. Laura and Grosson (1968) obtained fundamental frequencies for vibration of simply supported rhombic plates using conformal mapping and Galerkin's method, and compared their results with Conway and Farnham (1965). The difference increases with the skew angle. Monforton (1968) obtained fundamental frequencies of clamped rhombic plates by using FEM. The frequencies and mode shapes of clamped skew plates were studied by Durvasula (1969) using Galerkin's method. The deflection function was expressed as a double series of beam characteristic functions in terms of skew coordinates to satisfy zero deflection and normal slope on all the edges. Some interesting results were obtained and compared with the results of Kaul and Cadambe (1956), Hasegawa (1957) and Conway and Farnham (1965). Thangam Babu and 
Reddy (1971) investigated the free vibration of orthotropic skew plates with two opposite edges simply supported and the other two edges free. Nair and Durvasula (1973) reported the frequencies of isotropic and orthotropic skew plates for simply supported, clamped, free edge boundary condition and for combination of the above three edge conditions. Srinivasan and Ramachandran (1975) employed a numerical method to study variations of frequencies and mode shapes of orthotropic skew plates. Kuttler and Sigillito (1980) have used trial function method to solve vibration problem of skew plates.

Mizusuwa et al. $(1979,1980)$ and Mizusuwa and Kajita(1986,1987) employed the Rayleigh-Ritz method with B-spline functions to study the effect of skew angle and location of point supports on natural frequencies of isotropic skew plates. Liew and Lam (1990) used a set of 2-D orthogonal plate functions as an admissible deflection function to study the flexural vibration of skew plates using Rayleigh-Ritz method and obtained the results for four rhombic plates with different support conditions. Bardell (1992) adopted the hierarchical finite element method to determine natural frequencies and mode shapes of isotropic skew plates. Liew and Wang (1993) employed the Rayleigh-Ritz method and obtained results for four rhombic plates with different support conditions by changing internal support, skew angle and aspect ratio. Singh and Chakraverthy (1994) evaluated the first five frequencies for the transverse vibration of skew plates under different boundary conditions by using boundary characteristics orthogonal polynomials. McGee and Butalia (1994) studied the free vibration of thick and thin cantilever skew plates using $\mathrm{C}^{0}$ continuous isoparametric quadrilateral elements

Though vast literature on the free vibration of isotropic and orthotropic skew plates is available, few studies on free vibration of composite skew plates have been made. Kamal and Durvasula (1986) studied the free vibration characteristics of composite laminates using the modified shear deformation layered composite theory by employing Rayleigh-Ritz energy approach. Malhotra et al. (1988) studied the rhombic orthotropic plates using a parallelogrammic orthotropic plate finite element for various boundary conditions and skew angles. Krishnan and Deshpande (1992) adopted DKT finite element to demonstrate the effect of fiber orientation angle, skew angle, aspect ratio and length to thickness ratio on the fundamental frequencies of single layer graphite/epoxy and glass/epoxy skew plates. Krishna Reddy (1999) used a general high precision triangular bending element to study free vibration of laminated skew plates. A consistent mass matrix in explicit form is used for the study. Singha and Ganapathi (2004) studied the large amplitude free flexural vibrations of laminated composite skew plates using FE approach. Garg et.al. (2006) have presented the free vibration studies on isotropic, orthotropic, and layered anisotropic composite and sandwich skew laminates using isoparametric finite element model.

This paper deals with the studies on fundamental flexural frequencies of isotropic and laminated composite skew plates using CQUAD4 and CQUAD8 finite elements. The accuracy of the elements has been verified with literature values. The effects of skew angle, fiber orientation angle, number of layers in the laminate, laminate sequence and boundary conditions on the fundamental frequencies of skew plate are investigated.

\section{Convergence and Validation Studies}

\subsection{Convergence Study}

The geometry of the skew plate with global and local coordinate systems is shown in the Figure 1 in which $u$ and $v$ are the displacement variables in $x$ and $y$ directions respectively. Since $u$ and $v$ are inclined to the skew edges, the displacement boundary conditions cannot be applied directly. In order to overcome this, a local coordinate system $\left(x^{\prime}, y^{\prime}\right)$ normal and tangential to the skew edges is chosen. To obtain accurate and reliable results, it is necessary to study the convergence of the results so as to establish the optimum number of elements required in the finite element model. The convergence study has been performed on simply supported(S-S-S-S) (S3) (Jones, 1975) and clamped(C-C-C-C) (C2) (Jones, 1975) skew plates having aspect ratio (=a/b) of 1.0 and skew angles $0^{\circ}, 15^{\circ}, 30^{\circ}$ and $45^{\circ}$ using CQUAD4 (four-noded) and CQUAD8 (eight-noded isoparametric curved shell element) elements. The convergence details are furnished in Table 1.

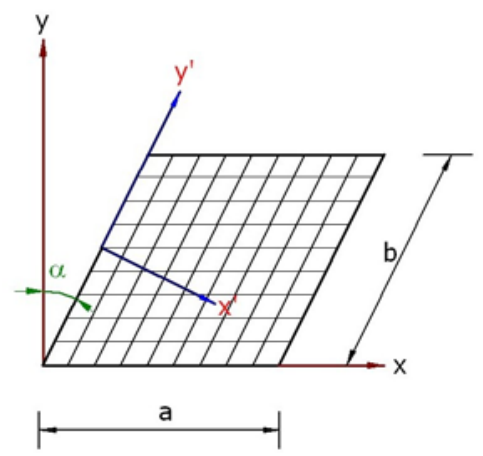

Figure 1: Global and Local Coordinate Systems for the Skew Plate with Finite Element Mesh. 
Table 1: Convergence study for fundamental frequency coefficients $\left(k_{f}\right)$ for isotropic skew plates $(\mathrm{a} / \mathrm{b}=1, \mathrm{a} / \mathrm{t}=100)$

\begin{tabular}{|c|c|c|c|c|c|c|c|c|c|}
\hline \multirow{3}{*}{\multicolumn{2}{|c|}{ AUTHOURS }} & \multicolumn{4}{|c|}{ S-S-S-S } & \multicolumn{4}{|c|}{ C-C-C-C } \\
\hline & & \multicolumn{4}{|c|}{ Skew Angle ( $\alpha$ ) } & \multicolumn{4}{|c|}{ Skew Angle ( $\alpha$ ) } \\
\hline & & $0^{0}$ & $15^{0}$ & $30^{\circ}$ & $45^{\circ}$ & $\mathbf{0}^{\mathbf{0}}$ & $15^{0}$ & $30^{\circ}$ & $45^{\circ}$ \\
\hline \multirow{2}{*}{ PRESENT(4X4) } & CQUAD4 & 1.8856 & 2.0056 & 2.4387 & 3.5260 & 3.5680 & 3.7813 & 4.5350 & 6.3136 \\
\hline & CQUAD8 & 1.9984 & 2.1262 & 2.6021 & 3.8474 & 3.6990 & 3.9250 & 4.7589 & 6.8829 \\
\hline \multirow{2}{*}{ PRESENT(6X6) } & CQUAD4 & 1.9367 & 2.0534 & 2.4755 & 3.5293 & 3.5264 & 3.7374 & 4.4879 & 6.2998 \\
\hline & CQUAD8 & 1.9988 & 2.1186 & 2.5653 & 3.7326 & 3.6489 & 3.8749 & 4.6853 & 6.6984 \\
\hline \multirow{2}{*}{ PRESENT(8X8) } & CQUAD4 & 1.9598 & 2.0756 & 2.4949 & 3.5406 & 3.5480 & 3.7617 & 4.5247 & 6.3843 \\
\hline & CQUAD8 & 1.9991 & 2.1166 & 2.5521 & 3.6839 & 3.6432 & 3.8669 & 4.6693 & 6.6576 \\
\hline \multirow{2}{*}{ PRESENT(10X10) } & CQUAD4 & 1.9724 & 2.0879 & 2.5057 & 3.5475 & 3.5702 & 3.7862 & 4.5587 & 6.4505 \\
\hline & CQUAD8 & 1.9993 & 2.1158 & 2.5452 & 3.6560 & 3.6422 & 3.8651 & 4.6651 & 6.6452 \\
\hline \multirow{2}{*}{ PRESENT(12X12) } & CQUAD4 & 1.9801 & 2.0953 & 2.5120 & 3.5510 & 3.5869 & 3.8045 & 4.5835 & 6.4966 \\
\hline & CQUAD8 & 1.9994 & 2.1153 & 2.5409 & 3.6375 & 3.6420 & 3.8646 & 4.6638 & 6.6408 \\
\hline \multirow{2}{*}{ PRESENT(14X14) } & CQUAD4 & 1.9849 & 2.1001 & 2.5159 & 3.5524 & 3.5990 & 3.8177 & 4.6012 & 6.5285 \\
\hline & CQUAD8 & 1.9995 & 2.1149 & 2.5379 & 3.6241 & 3.6419 & 3.8645 & 4.6634 & 6.6391 \\
\hline \multirow{2}{*}{ PRESENT(16X16) } & CQUAD4 & 1.9882 & 2.1032 & 2.5164 & 3.5527 & 3.6077 & 3.8272 & 4.6138 & 6.5511 \\
\hline & CQUAD8 & 1.9995 & 2.1147 & 2.5357 & 3.6139 & 3.6419 & 3.8645 & 4.6632 & 6.6383 \\
\hline \multirow{2}{*}{ PRESENT(18X18) } & CQUAD4 & 1.9905 & 2.1055 & 2.5173 & 3.5523 & 3.6141 & 3.8342 & 4.6231 & 6.5675 \\
\hline & CQUAD8 & 1.9996 & 2.1145 & 2.5341 & 3.6057 & 3.6419 & 3.8645 & 4.6632 & 6.6379 \\
\hline \multirow{2}{*}{ PRESENT(20X20) } & CQUAD4 & 1.9922 & 2.1070 & 2.5189 & 3.5516 & 3.6190 & 3.8395 & 4.6301 & 6.5798 \\
\hline & CQUAD8 & 2.0000 & 2.1144 & 2.5327 & 3.5991 & 3.6420 & 3.8645 & 4.6632 & 6.6378 \\
\hline \multicolumn{2}{|c|}{ Durvasula (1969) } & 2.0000 & 2.1100 & 2.5200 & 3.5300 & 3.6467 & 3.8700 & 4.6750 & 6.6800 \\
\hline \multicolumn{2}{|c|}{ Liew \&Lam(1990) } & 2.0000 & 2.1100 & 2.5400 & 3.5400 & 3.6360 & 3.8691 & 4.6698 & 6.6519 \\
\hline \multicolumn{2}{|c|}{ Krishna Reddy(1999) } & 2.0000 & 2.1200 & 2.5300 & 3.5100 & 3.6380 & 3.8720 & 4.6720 & 6.6630 \\
\hline \multicolumn{2}{|c|}{ A. K. Garg et al.(2006) } & 2.0000 & 2.1150 & 2.5240 & 3.6290 & 3.6480 & 3.8720 & 4.6800 & 6.6990 \\
\hline
\end{tabular}

\subsection{Validation Check}

The validation for the present elements is performed by comparing the values for the non-dimensional fundamental frequency coefficient $\left(K_{f}\right)$ obtained in this work with those available in literature. The same is presented in Table 2 for simply supported(S-S$\mathrm{S}-\mathrm{S})$ and in Table 3 for clamped(C-C-C-C) isotropic skew plates. It can be seen from Tables 2 and 3 that the results obtained using the present elements are in good agreement with the literature values. In a similar manner validation check is performed on square antisymmetric graphite/epoxy angle-ply laminates with different fiber angle $\left(0^{\circ}\right.$ to $\left.90^{\circ}\right)$ and different number of layers while keeping the total thickness constant. The material properties used are: $E_{l} / E_{t}=40, \mathrm{G}_{l t} / E_{t}=0.5$ and $v_{l t}=0.25$. The values of fundamental frequencies are compared with those available in the literature and are presented in Table 4 . The $K_{f}$ values obtained are in good agreement with those available in the literature. From Table 4 it can be seen that CQUAD8 element yields better results when compared with the CQUAD4 element. Hence CQUAD8 element is employed in the present work for further study.

Table 2: Fundamental frequencies of isotropic simply supported(S-S-S-S) skew plates

\begin{tabular}{|c|c|c|c|c|c|}
\hline \multirow{3}{*}{\multicolumn{2}{|c|}{ AUTHORS }} & \multicolumn{4}{|c|}{$\begin{array}{l}\text { Non-dimensional Fundamental } \\
\text { Frequencies Coefficients }\left(K_{f}\right)\end{array}$} \\
\hline & & \multicolumn{4}{|c|}{ Skew angle $(\alpha)$} \\
\hline & & $0^{\circ}$ & $15^{\circ}$ & $30^{\circ}$ & $45^{\circ}$ \\
\hline \multicolumn{2}{|c|}{ Durvasula (1969) } & 2.000 & 2.110 & 2.520 & 3.530 \\
\hline \multicolumn{2}{|c|}{ Liew \&Lam(1990) } & 2.000 & 2.110 & 2.540 & 3.540 \\
\hline \multicolumn{2}{|c|}{ Liew et.al(1993) } & 2.000 & - & 2.530 & - \\
\hline \multicolumn{2}{|c|}{ Krishnan et.al (1992) } & 2.000 & 2.120 & 2.520 & 3.450 \\
\hline \multicolumn{2}{|c|}{ Krishna Reddy (1999) } & 2.000 & 2.120 & 2.530 & 3.510 \\
\hline \multicolumn{2}{|c|}{ Garg A. K. et al.(2006) } & 2.000 & 2.115 & 2.524 & 3.629 \\
\hline \multirow{2}{*}{ Present } & CQUAD8 & 2.000 & 2.114 & 2.533 & 3.599 \\
\hline & CQUAD4 & 1.992 & 2.107 & 2.519 & 3.551 \\
\hline
\end{tabular}


Table 3: Fundamental frequencies of isotropic clamped(C-C-C-C) skew plates

\begin{tabular}{|c|c|c|c|c|c|}
\hline \multirow{3}{*}{\multicolumn{2}{|c|}{ AUTHORS }} & \multirow{2}{*}{\multicolumn{4}{|c|}{$\begin{array}{l}\text { Non-dimensional Fundamental } \\
\text { Frequencies Coefficients }\left(K_{f}\right)\end{array}$}} \\
\hline & & & & & \\
\hline & & $0^{\circ}$ & $15^{\circ}$ & $30^{\circ}$ & $45^{\circ}$ \\
\hline \multicolumn{2}{|c|}{ Hasegawa (1957) } & 3.647 & 3.879 & 4.678 & - \\
\hline \multicolumn{2}{|c|}{ Hamada (1959) } & - & 3.868 & 4.669 & 6.645 \\
\hline \multicolumn{2}{|c|}{ Conway (1965) } & 3.648 & 3.872 & 4.682 & 6.651 \\
\hline \multicolumn{2}{|c|}{ Monforton (1968) } & 3.646 & 3.870 & 4.673 & 6.670 \\
\hline \multicolumn{2}{|c|}{ Durvasula (1969) } & 3.646 & 3.870 & 4.675 & 6.680 \\
\hline \multicolumn{2}{|c|}{ Mizusuwa et. al(1979) } & 3.646 & - & 4.669 & 6.642 \\
\hline \multicolumn{2}{|c|}{ Bardell(1992) } & 3.646 & 3.869 & 4.670 & 6.651 \\
\hline \multicolumn{2}{|c|}{ Liew \&Lam(1993) } & 3.636 & 3.869 & 4.669 & 6.652 \\
\hline \multicolumn{2}{|c|}{ Singh et.al (1994) } & - & - & 4.678 & 6.720 \\
\hline \multicolumn{2}{|c|}{ Krishna Reddy(1999) } & 3.638 & 3.872 & 4.672 & 6.663 \\
\hline \multicolumn{2}{|c|}{ Garg et al.(2006) } & 3.648 & 3.872 & 4.680 & 6.699 \\
\hline \multirow{2}{*}{ Present } & CQUAD8 & 3.642 & 3.864 & 4.663 & 6.638 \\
\hline & CQUAD4 & 3.619 & 3.840 & 4.630 & 6.580 \\
\hline
\end{tabular}

Table 4: Fundamental frequencies of simply supported square antisymmetric angle-ply laminates

\begin{tabular}{|c|c|c|c|c|c|c|c|c|c|c|c|c|}
\hline \multirow{3}{*}{$\begin{array}{c}\text { Fiber } \\
\text { Angle } \\
(\theta)\end{array}$} & \multicolumn{4}{|c|}{ Number of Layers(NL)=2 } & \multicolumn{4}{|c|}{ Number of Layers(NL)=4 } & \multicolumn{4}{|c|}{ Number of Layers(NL) $=6$} \\
\hline & \multirow{2}{*}{$\begin{array}{l}\text { Jones } \\
\text { (1975) }\end{array}$} & \multirow{2}{*}{$\begin{array}{l}\text { Reddy } \\
\text { (1999) }\end{array}$} & \multicolumn{2}{|c|}{ Present } & \multirow{2}{*}{$\begin{array}{l}\text { Jones } \\
\text { (1975) }\end{array}$} & \multirow{2}{*}{$\begin{array}{l}\text { Reddy } \\
\text { (1999) }\end{array}$} & \multicolumn{2}{|c|}{ Present } & \multirow{2}{*}{$\begin{array}{l}\text { Jones } \\
\text { (1975) }\end{array}$} & \multirow{2}{*}{$\begin{array}{l}\text { Reddy } \\
\text { (1999) }\end{array}$} & \multicolumn{2}{|c|}{ Present } \\
\hline & & & CQUAD8 & CQUAD4 & & & CQUAD8 & CQUAD4 & & & CQUAD8 & CQUAD4 \\
\hline $0^{\circ}$ & 18.805 & 18.806 & 18.804 & 18.685 & 18.806 & 18.806 & 18.804 & 18.685 & 18.805 & 18.806 & 18.804 & 18.685 \\
\hline $15^{\circ}$ & 14.646 & 14.646 & 14.645 & 14.528 & 19.431 & 19.431 & 19.430 & 19.278 & 20.192 & 20.193 & 20.190 & 20.033 \\
\hline $30^{\circ}$ & 14.204 & 14.204 & 14.203 & 14.075 & 22.176 & 22.175 & 22.172 & 21.974 & 23.355 & 23.355 & 23.353 & 23.137 \\
\hline $45^{\circ}$ & 14.638 & 14.638 & 14.637 & 14.506 & 23.258 & 23.258 & 23.256 & 23.028 & 24.827 & 24.828 & 24.825 & 24.072 \\
\hline $60^{\circ}$ & 14.204 & 14.204 & 14.203 & 14.075 & 22.176 & 22.175 & 22.172 & 21.974 & 23.355 & 23.355 & 23.353 & 23.137 \\
\hline $75^{\circ}$ & 14.646 & 14.646 & 14.645 & 14.528 & 19.431 & 19.431 & 19.430 & 19.278 & 20.192 & 20.193 & 20.190 & 20.033 \\
\hline $90^{\circ}$ & 18.805 & 18.806 & 18.804 & 18.685 & 18.806 & 18.806 & 18.804 & 18.685 & 18.805 & 18.806 & 18.804 & 18.685 \\
\hline
\end{tabular}

\section{Results and Discussions}

The results of the present work are presented in the form of non-dimensional fundamental frequency coefficient $\left(K_{f}\right)$ as $K_{f}=\frac{\omega a^{2}}{\pi^{2}} \sqrt{\frac{\rho t}{D}}$ for isotropic and $K_{f}=\omega a^{2} \sqrt{\frac{\rho_{1}}{E_{t} t^{3}}}$ for laminated composites for the following cases:

1) Simply supported and clamped isotropic skew plates and

2) Simply supported and clamped antisymmetric angle and cross-ply laminates.

\subsection{Simply Supported and Clamped Isotropic Skew Plates}

Numerical studies have been made for a number of skew plates with different aspect ratios, skew angles, and length-thickness ratio with simply supported and clamped boundary conditions. The results obtained are tabulated in Table 5 in the form of nondimensional frequency coefficients $\left(K_{f}\right)$. It is seen that $K_{f}$ increases as the aspect ratio $(\mathrm{a} / \mathrm{b})$, skew angles $(\alpha)$ increases. It can also be observed that $K_{f}$ increases as the skew angle $\alpha$ increases for constant values of a/b and a/t. $K_{f}$ decreases as a/t decreases for constant $\mathrm{a} / \mathrm{b}$ ratio and skew angle. 
Table 5: Free vibration of simply supported and clamped isotropic skew plates

\begin{tabular}{|c|c|c|c|c|c|c|c|c|c|}
\hline \multirow{4}{*}{$\mathrm{a} / \mathrm{b}$} & \multirow{4}{*}{$\mathrm{a} / \mathrm{t}$} & \multicolumn{8}{|c|}{ Non-dimensional fundamental frequencies coefficients $\left(K_{f}\right)$} \\
\hline & & \multicolumn{8}{|c|}{ Skew angle $(\alpha)$} \\
\hline & & $0^{\circ}$ & $15^{\circ}$ & $30^{\circ}$ & $45^{\circ}$ & $0^{\circ}$ & $15^{\circ}$ & $30^{\circ}$ & $45^{\circ}$ \\
\hline & & \multicolumn{4}{|c|}{ S-S-S-S } & \multicolumn{4}{|c|}{$\mathrm{C}-\mathrm{C}-\mathrm{C}-\mathrm{C}$} \\
\hline \multirow{5}{*}{0.5} & 1000 & 1.2477 & 1.3234 & 1.6108 & 2.3318 & 2.4901 & 2.6568 & 3.2619 & 4.7958 \\
\hline & 500 & 1.2476 & 1.3234 & 1.6106 & 2.3314 & 2.4900 & 2.6567 & 3.2618 & 4.7956 \\
\hline & 100 & 1.2462 & 1.3218 & 1.6071 & 2.3228 & 2.4882 & 2.6545 & 3.2584 & 4.7881 \\
\hline & 50 & 1.2432 & 1.3187 & 1.6010 & 2.3090 & 2.4823 & 2.6840 & 3.2484 & 4.7664 \\
\hline & 20 & 1.2306 & 1.3058 & 1.5808 & 2.2695 & 2.4437 & 2.6039 & 3.1824 & 4.6264 \\
\hline \multirow{5}{*}{1.0} & 1000 & 1.9968 & 2.1171 & 2.5376 & 3.6084 & 3.6460 & 3.8691 & 4.6700 & 6.6470 \\
\hline & 500 & 1.9964 & 2.1166 & 2.5364 & 3.6048 & 3.6459 & 3.8689 & 4.6697 & 6.6514 \\
\hline & 100 & 1.9998 & 2.1144 & 2.5327 & 3.5991 & 3.6420 & 3.8645 & 4.6632 & 6.6378 \\
\hline & 50 & 1.9784 & 2.0872 & 2.4873 & 3.4691 & 3.6278 & 3.8488 & 4.6410 & 6.5947 \\
\hline & 20 & 1.9432 & 2.0489 & 2.4314 & 3.3651 & 3.5523 & 3.7640 & 4.5183 & 6.3513 \\
\hline \multirow{5}{*}{1.5} & 1000 & 3.2437 & 3.4361 & 4.1391 & 5.9022 & 6.1589 & 6.5527 & 7.9756 & 11.5494 \\
\hline & 500 & 3.2450 & 3.4332 & 4.1349 & 5.8889 & 6.1559 & 6.5494 & 7.9714 & 11.5429 \\
\hline & 100 & 3.2326 & 3.4199 & 4.1063 & 5.8130 & 6.1448 & 6.5368 & 7.9526 & 11.5033 \\
\hline & 50 & 3.2114 & 3.3967 & 4.0698 & 5.7397 & 6.1071 & 6.4944 & 7.8912 & 11.3782 \\
\hline & 20 & 3.1412 & 3.3184 & 3.9661 & 5.5631 & 5.5816 & 6.2515 & 7.5363 & 10.6588 \\
\hline \multirow{5}{*}{2.0} & 1000 & 5.007 & 5.3157 & 6.4519 & 9.3249 & 9.9855 & 10.6534 & 13.0788 & 19.2264 \\
\hline & 500 & 4.9946 & 5.3012 & 6.4319 & 9.2913 & 9.9597 & 10.6258 & 13.0446 & 19.1749 \\
\hline & 100 & 4.9751 & 5.2804 & 6.3943 & 9.2299 & 9.9303 & 10.5924 & 12.9942 & 19.0660 \\
\hline & 50 & 4.9412 & 5.2436 & 6.3413 & 9.1459 & 9.8347 & 10.4840 & 12.8336 & 18.7285 \\
\hline & 20 & 4.8162 & 5.1066 & 6.1596 & 8.8335 & 9.2814 & 9.8587 & 11.9133 & 16.8754 \\
\hline \multirow{5}{*}{2.5} & 1000 & 7.2497 & 7.7058 & 9.4085 & 13.7191 & 14.9630 & 15.9898 & 19.7243 & 29.2190 \\
\hline & 500 & 7.2433 & 7.7079 & 9.4092 & 13.7138 & 14.9697 & 15.9967 & 19.7322 & 29.2281 \\
\hline & 100 & 7.2158 & 7.6779 & 9.3604 & 13.6112 & 14.9035 & 15.9209 & 19.6168 & 28.9751 \\
\hline & 50 & 7.1636 & 7.6205 & 9.2826 & 13.4703 & 14.6926 & 15.6816 & 19.2586 & 28.2131 \\
\hline & 20 & 6.9539 & 7.3883 & 8.9606 & 9.6414 & 13.4964 & 14.3298 & 17.2780 & 24.2504 \\
\hline
\end{tabular}

\subsubsection{Antisymmetric Cross-Ply Skew Laminates}

The variations of fundamental frequency coefficient $\left(K_{f}\right)$ with respect to skew angle $(\alpha)$, fiber orientation angle $(\theta)$ and number of layers(NL) for graphite/epoxy antisymmetric cross-ply skew laminates are presented in Figures 2 and 3 respectively for simply supported (S3) (Jones, 1975) and clamped boundary conditions(C2) (Jones,1975). From Figures 2 and 3 it is seen that, as the skew angle increases, $K_{f}$ increases. For a given skew angle, it is seen that $K_{f}$ increases up to $\mathrm{NL}=4$ and remains constant thereafter.

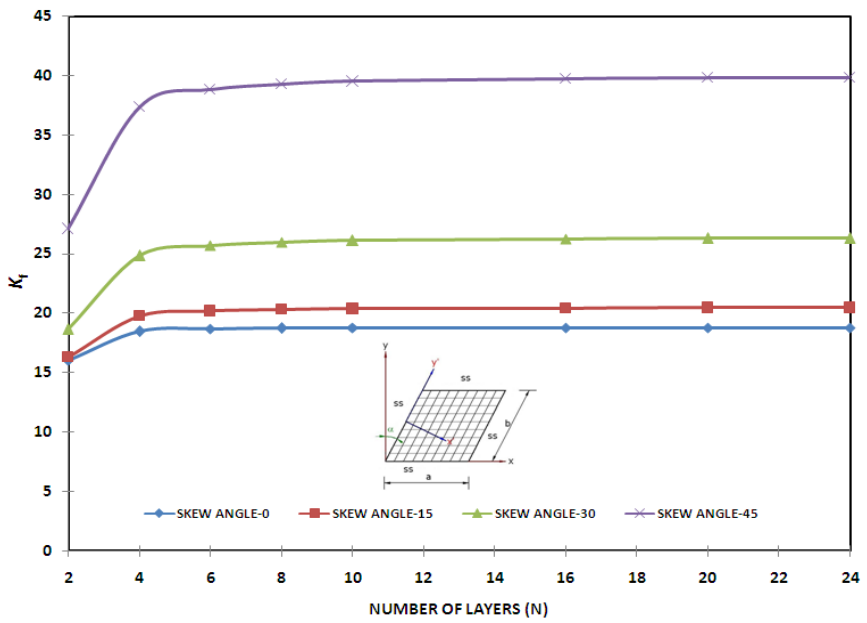

Figure 2: Values of $K_{f}$ for simply supported antisymmetric cross-ply skew laminates 


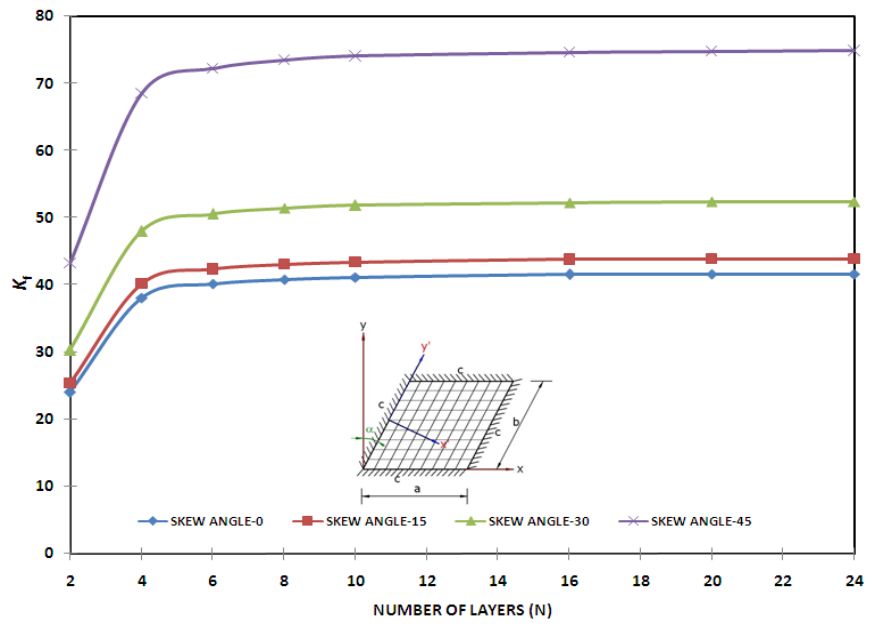

Figure 3: Values of $K_{f}$ for clamped antisymmetric cross-ply skew laminates.

\subsubsection{Antisymmetric Angle-Ply Skew Laminates}

\section{(a) Simply Supported Boundary Condition}

The variations of fundamental frequency coefficient $\left(K_{f}\right)$ with skew angle $(\alpha)$, fiber orientation angle $(\theta)$ and number of layers(NL) for antisymmetric angle-ply skew laminates under S3 boundary conditions are presented in Figures 4-7. For skew angles up to 45 degrees and $\mathrm{NL}=2, K_{f}$ initially decreases with fibre orientation angle and later varies as shown in Figures 4-7. For $\mathrm{NL} \geq 4$ and for all the skew angles, $K_{f}$ increases and reaches a maximum at about $\theta=45^{\circ}, 47^{\circ}, 50^{\circ}$ and $70^{\circ}$, for skew angles $=$ $0^{\circ}, 15^{\circ}, 30^{\circ}$ and $45^{\circ}$ respectively. It is observed that the variation of $K_{f}$ with $\theta$ is symmetric about $\theta=45^{\circ}$ for $\alpha=0^{\circ}$ and becomes asymmetric as $\alpha$ increases. The increase in $K_{f}$ with an increase in NL beyond $\mathrm{NL}=10$ is not appreciable in all the cases. The Frequency coefficient ratio $f_{r}$ defined as $f_{r}=\left[\left(K_{f}\right)_{\theta=0^{0}} /\left(K_{f}\right)_{\theta=90^{0}}\right]$, is unity for skew angle $\alpha=0^{\circ}$ (square plate) and its values for other skew angles are presented in Table 6. A perusal of Figures 4-7 indicates that $f_{r}$ decreases with the skew angle.

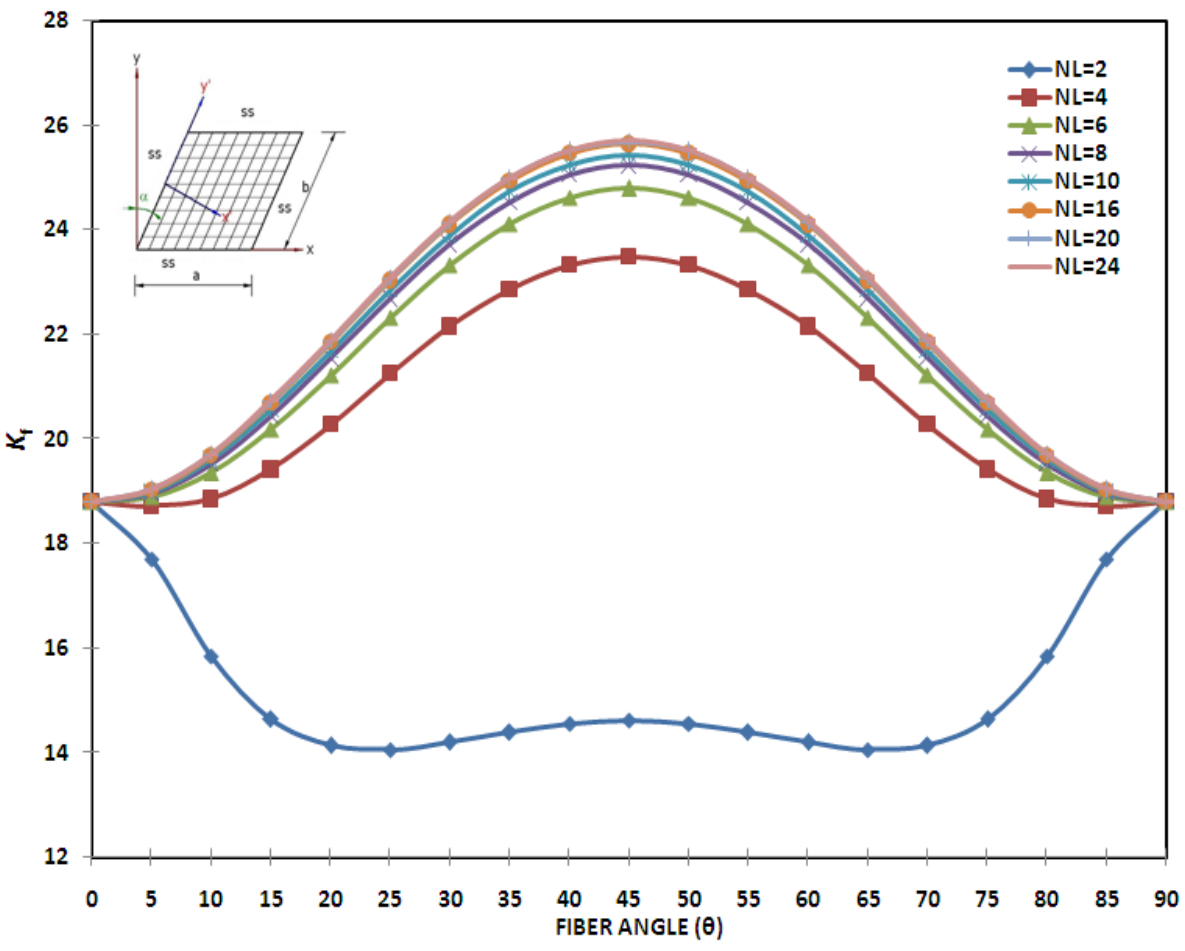

Figure 4: Values of $K_{f}$ for simply supported antisymmetric angle-ply skew laminates $\left(\alpha=0^{\circ}, \mathrm{S} 3, \mathrm{a} / \mathrm{b}=1\right.$, Graphite/Epoxy). 


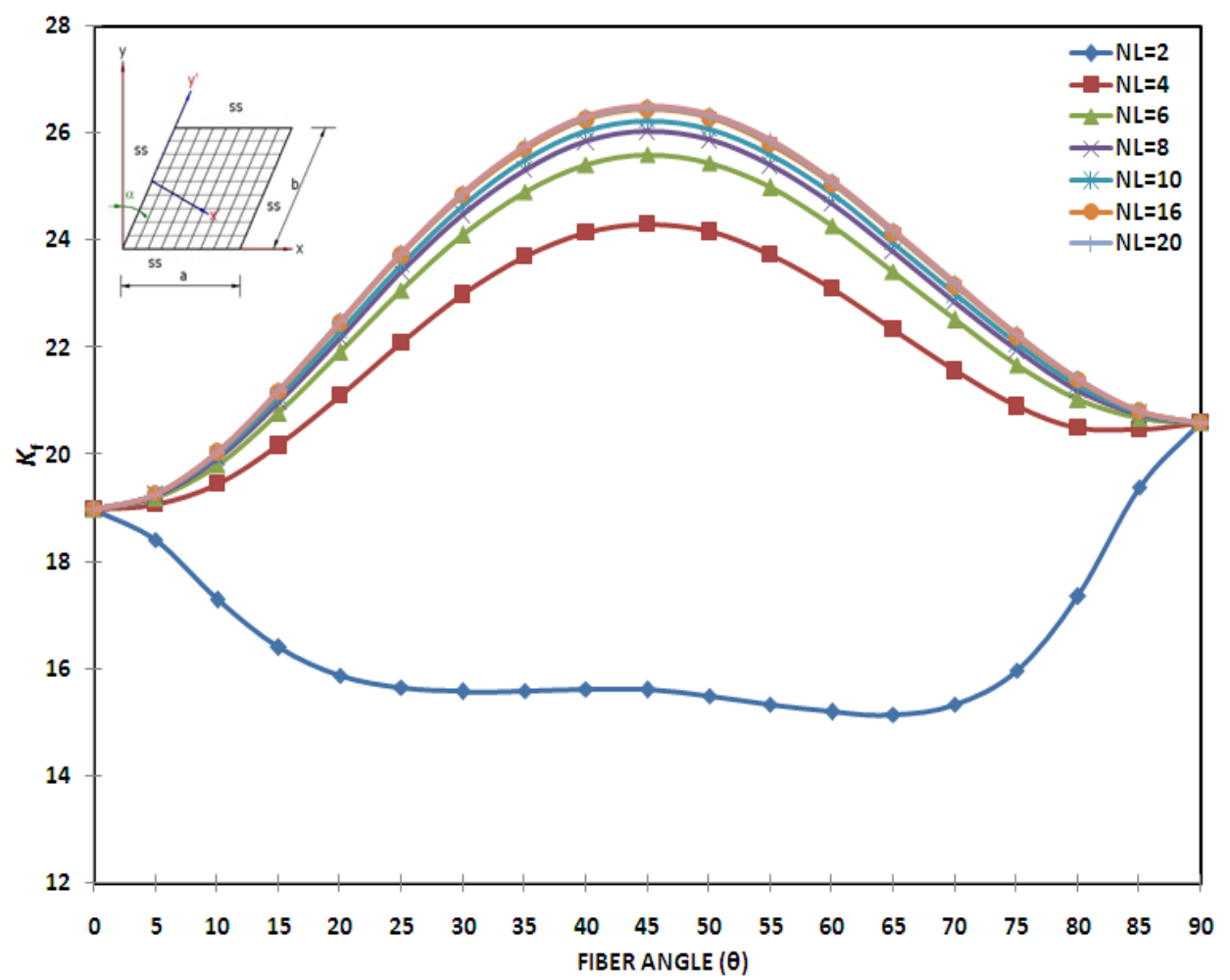

Figure 5: Values of $K_{f}$ for simply supported antisymmetric angle-ply skew laminates $\left(\alpha=15^{\circ}, \mathrm{S} 3, \mathrm{a} / \mathrm{b}=1\right.$, Graphite/Epoxy).

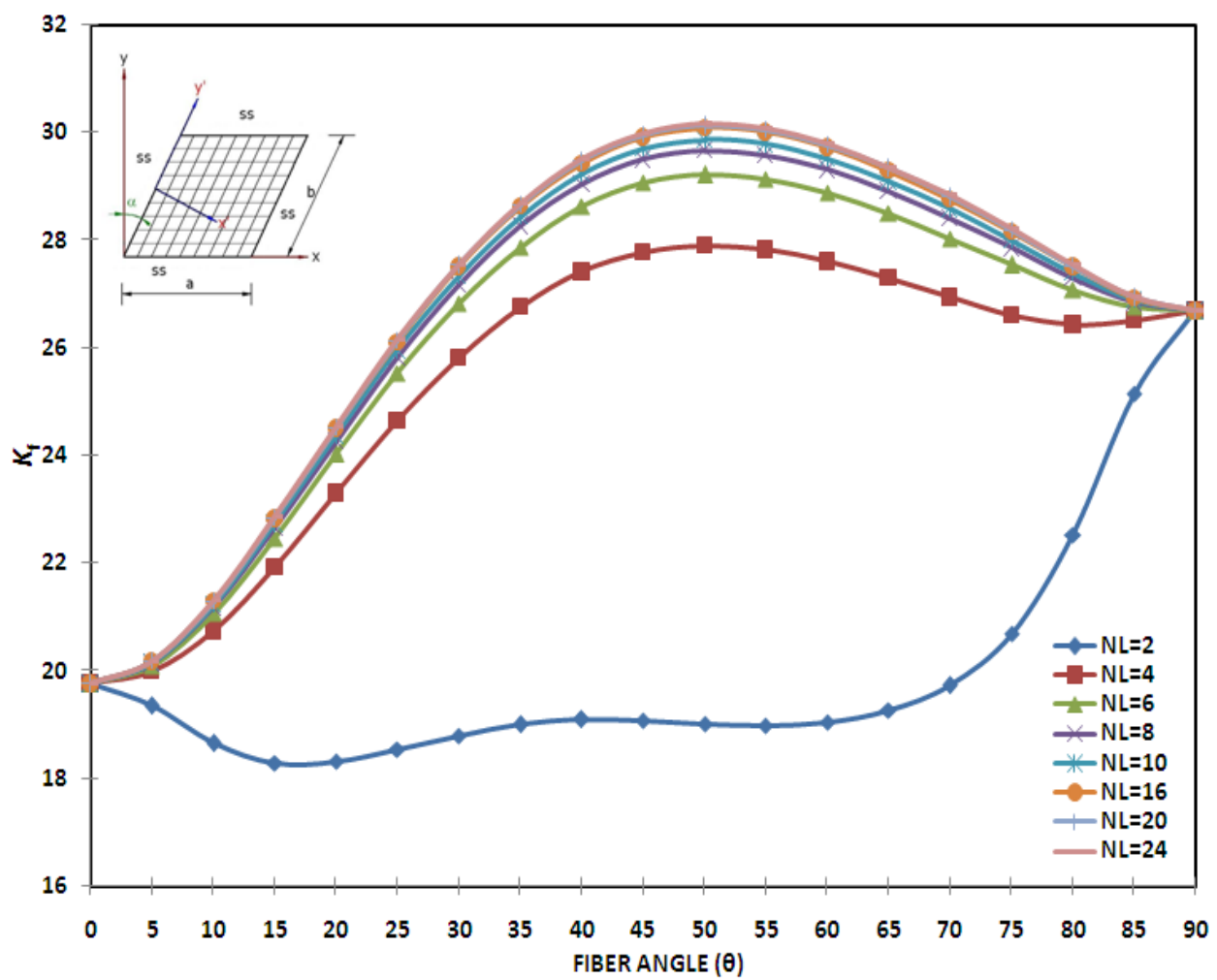

Figure 6: Values of $K_{f}$ for Simply Supported Antisymmetric Angle-Ply Skew Laminates $\left(\alpha=30^{\circ}, \mathrm{S} 3, \mathrm{a} / \mathrm{b}=1\right.$, Graphite/Epoxy). 


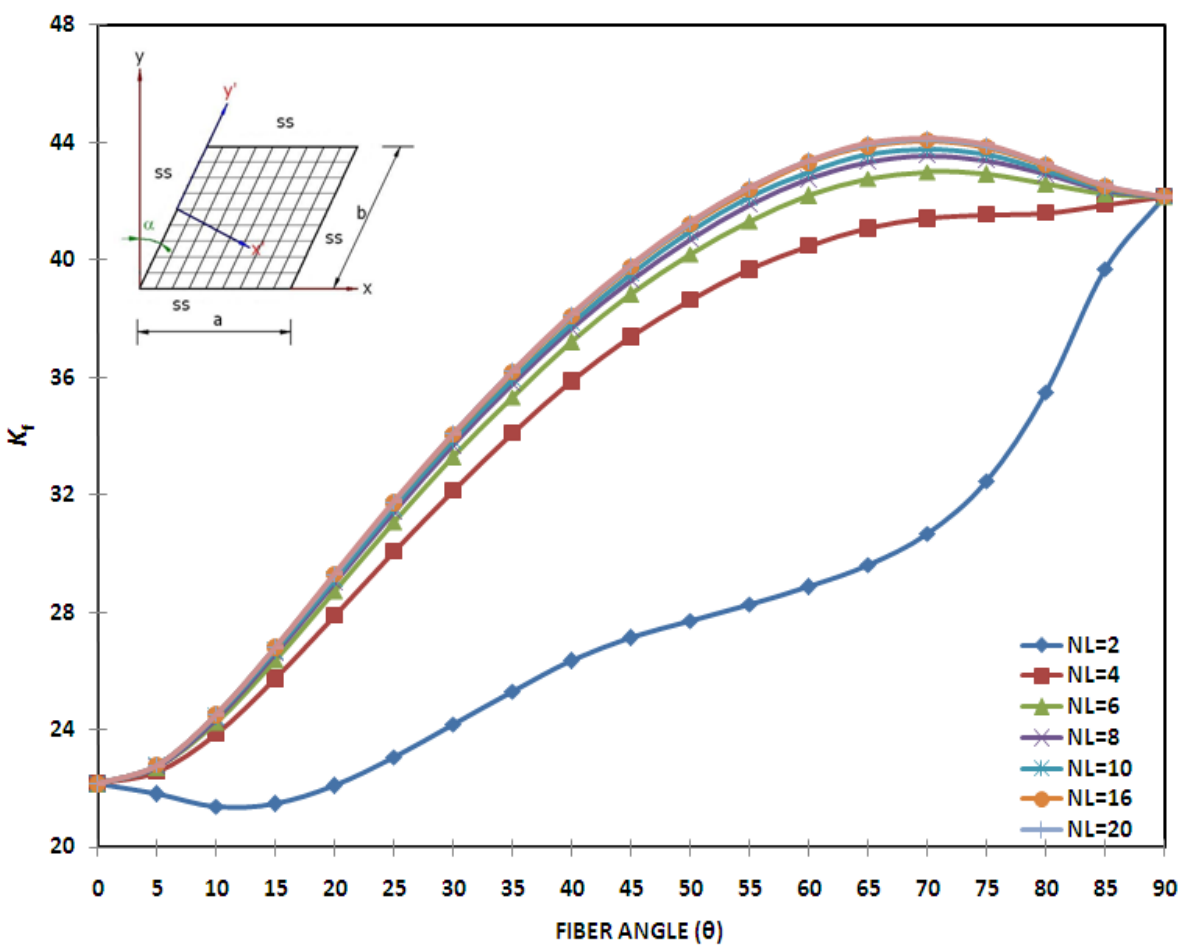

Figure 7: Values of $K_{f}$ for simply supported antisymmetric angle-ply skew laminates $\left(\alpha=45^{\circ}, \mathrm{S} 3, \mathrm{a} / \mathrm{b}=1\right.$, Graphite/Epoxy).

\section{(b) Clamped Boundary Condition}

For antisymmetric angle-ply skew plates of $\alpha=0^{\circ}, 15^{\circ}, 30^{\circ}$ and $45^{\circ}$, the variations of $K_{f}$ with $\theta$ and NL are presented in Figures 811. The variation of $K_{f}$ is symmetric at about $\theta=45^{\circ}$ line for $\alpha=0^{\circ}$ and becomes asymmetric for other skew angles. For NL $=2, K_{f}$ initially decreases and varies later as shown in Figures 8-11. The increase in $K_{f}$ with NL for NL greater than 10 is not appreciable. The $f_{r}$ values for various skew angles $(\alpha)$ are presented in Table 6 .

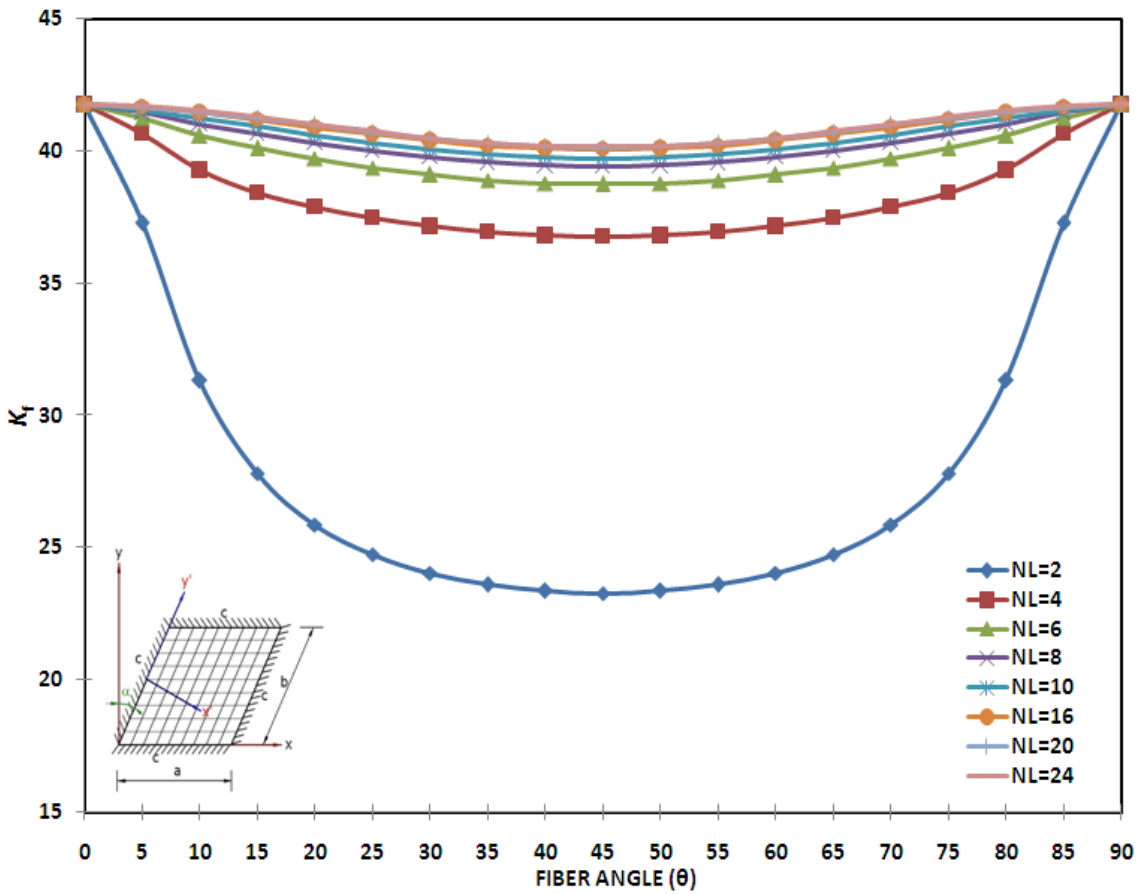

Figure 8: Values of $K_{f}$ for clamped supported antisymmetric angle-ply skew laminates $\left(\alpha=0^{\circ}, \mathrm{C} 2, \mathrm{a} / \mathrm{b}=1\right.$, Graphite/Epoxy). 


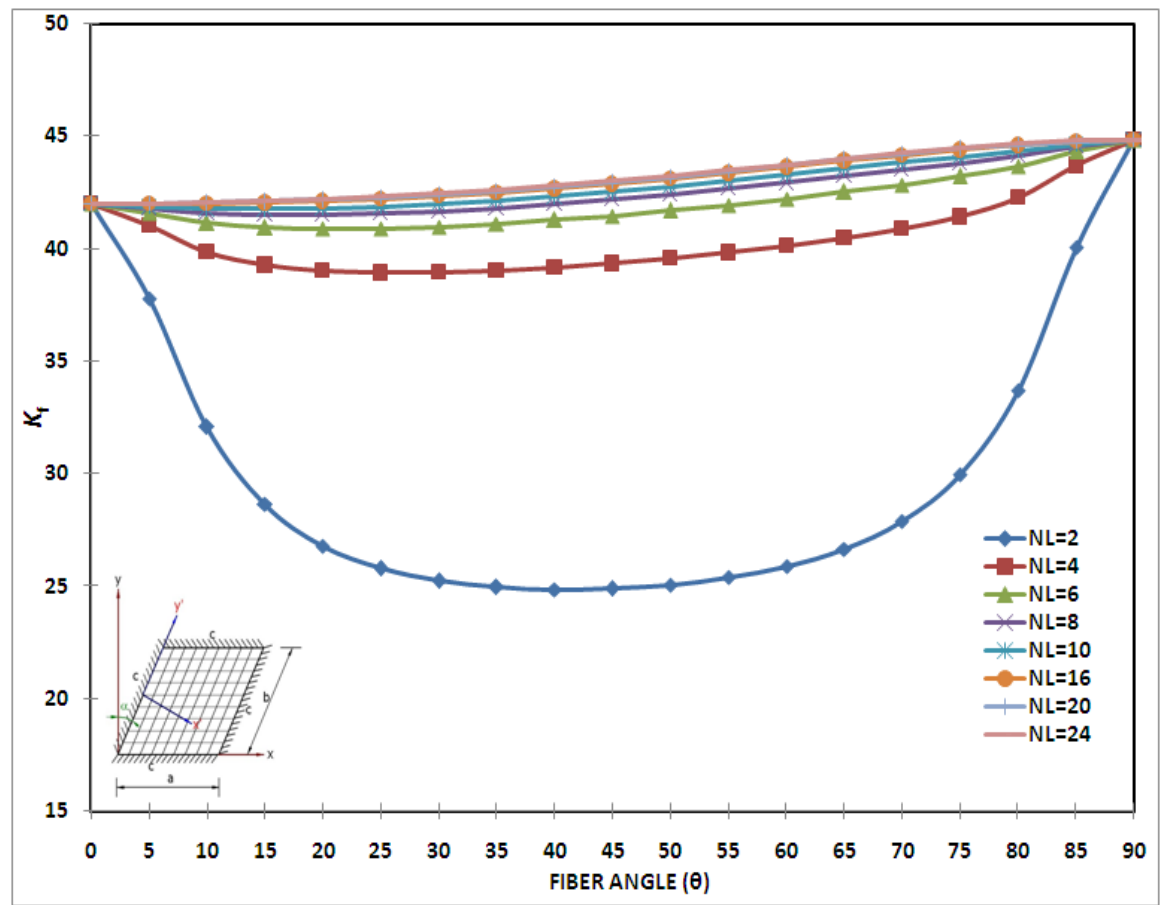

Figure 9: Values of $K_{f}$ for clamped supported antisymmetric angle-ply skew laminates $\left(\alpha=15^{\circ}, \mathrm{C} 2, \mathrm{a} / \mathrm{b}=1\right.$, Graphite/Epoxy)

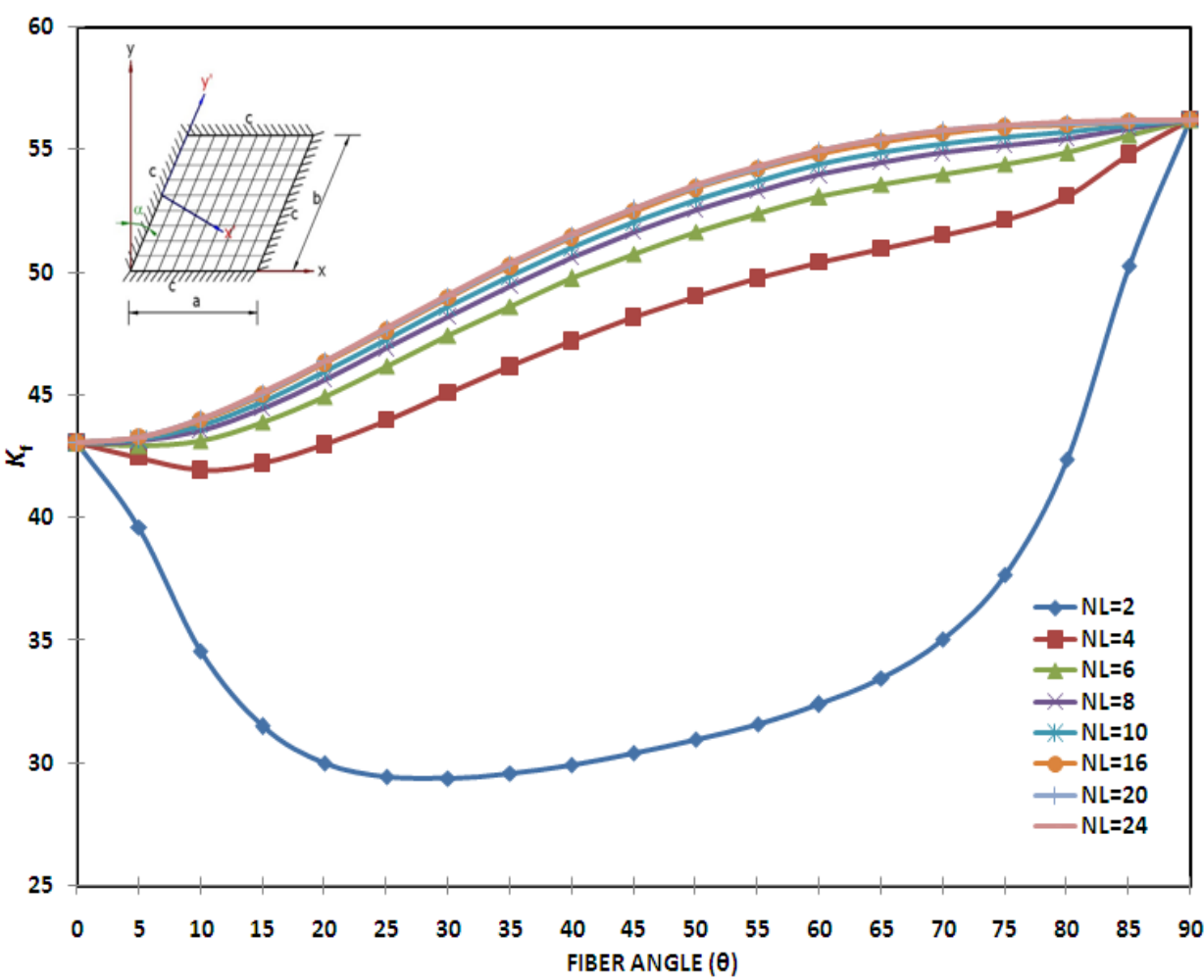

Figure 10: Values of $K_{f}$ for Clamped Supported Antisymmetric Angle-Ply Skew Laminates $\left(\alpha=30^{\circ}, \mathrm{C} 2, \mathrm{a} / \mathrm{b}=1\right.$, Graphite/Epoxy). 


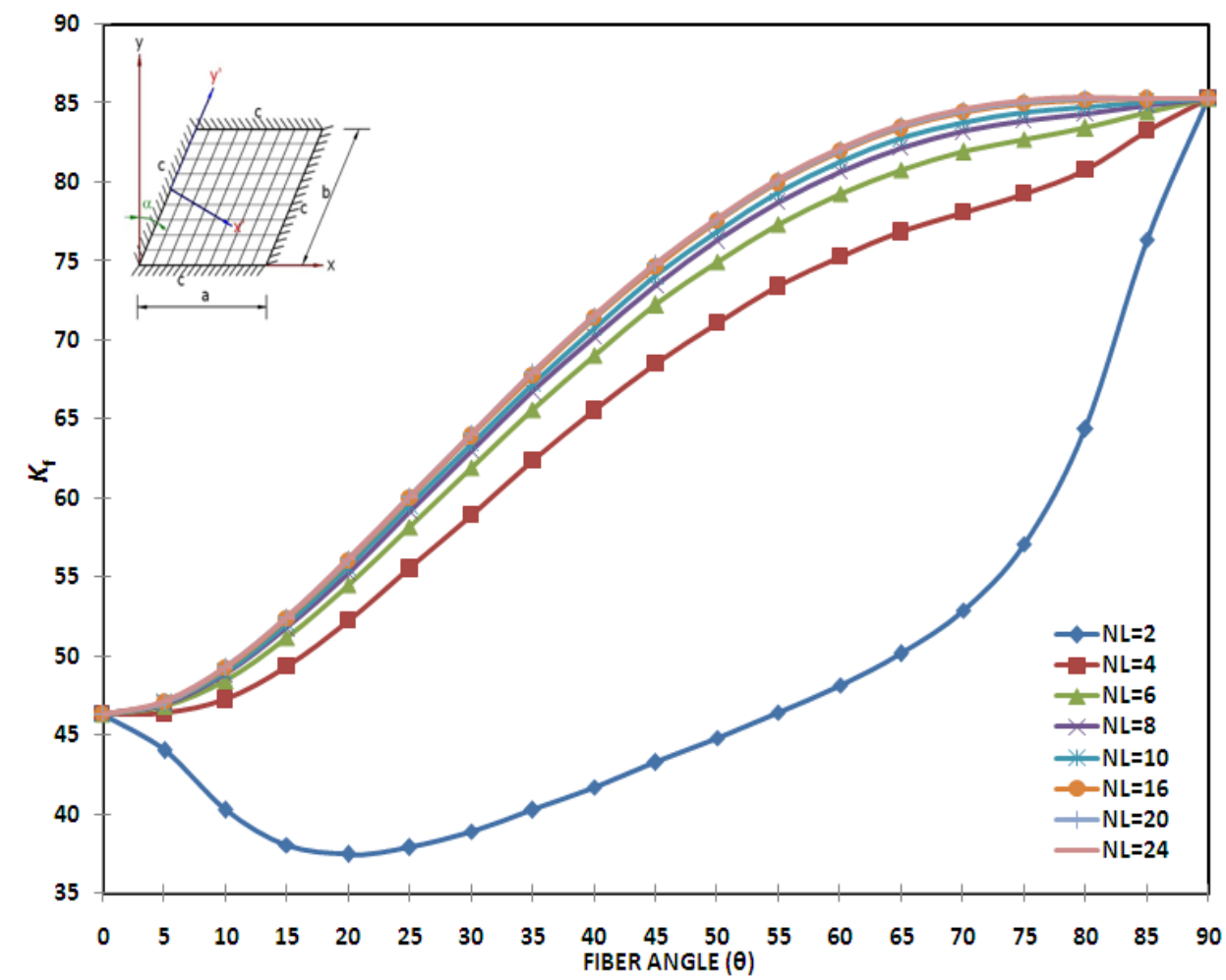

Figure 11: Values of $K_{f}$ for Clamped Supported Antisymmetric Angle-Ply Skew Laminates $\left(\alpha=45^{\circ}, \mathrm{C} 2, \mathrm{a} / \mathrm{b}=1\right.$, Graphite/Epoxy).

Table 6: $f_{r}$ Values for graphite/epoxy antisymmetric skew plates

\begin{tabular}{|c|c|c|c|c|}
\hline Boundary & \multicolumn{4}{|c|}{ Skew Angle $(\alpha)$} \\
\cline { 2 - 5 } Conditions & $0^{\circ}$ & $15^{\circ}$ & $30^{\circ}$ & $45^{\circ}$ \\
\hline S-S-S-S & 1.000 & 0.9219 & 0.7405 & 0.5252 \\
\hline C-C-C-C & 1.000 & 0.9365 & 0.7657 & 0.5433 \\
\hline
\end{tabular}

\section{Conclusions}

(i) The CQUAD8 element is seen to yield better results for the fundamental flexural frequencies of skew plates compared with the CQUAD4 element. Both the elements have been validated against available literature values.

(ii) In the case of cross-ply antisymmetric skew plate, it is seen that $K_{f}$ increases up to NL $=4$ and remains constant thereafter for a given skew angle.

(iii) In the case of simply supported and clamped antisymmetric skew plates, it is observed that the variation of $K_{f}$ with $\theta$ is symmetric at about $\theta=45^{\circ}$ for $\alpha=0^{\circ}$ and becomes asymmetric as $\alpha$ increases. The increase in $K_{f}$ with the number of layers beyond $\mathrm{NL}=10$ is not appreciable in all the cases.

(iv) The frequencies increase with the skew angle of the laminate.

(v) The value of $f_{r}$ decreases as the skew angle increases.

\section{Nomenclature:}

a : Plate length

b : Plate width

$t \quad$ : Plate thickness

$N L \quad$ : Number of layers

E : Modulus of elasticity 


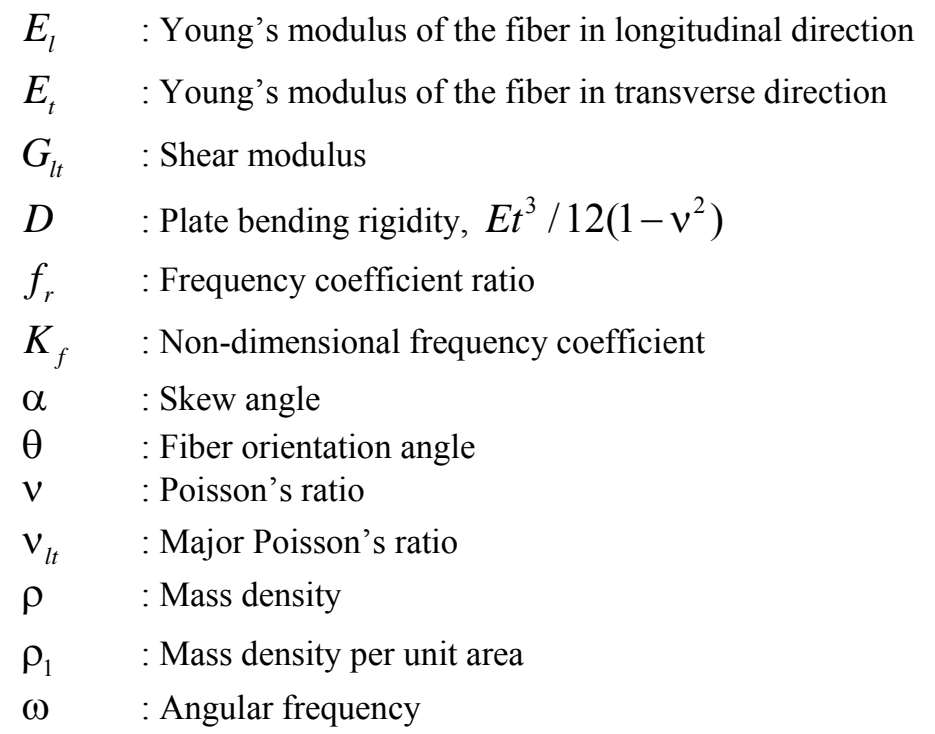

\section{Acknowledgments}

The first author would like to thank the Management and Principal of GM Institute of Technology, Davangere, Karnataka, for the kind encouragement and constant support provided. The second author would like to thank the Management of Jawaharlal Nehru College of Engineering, Shivamogga, India for the kind encouragement and facilities provided. The third author wishes to thank the Management, Director and Principal of Nagarjuna College of Engineering \& Technology, Bangalore for the kind encouragement and support provided.

\section{References}

Barton. M.V., 1951. Vibration of Rectangular and Skew Cantilever Plates, Journal of Applied Mechanics, ASME, vol. 18, pp.129134.

Bardell. N.S., 1992. The Free Vibration of Skew Plates Using the Hierarchical Finite Element Method, Computer and Structures, vol. 45, pp 841-874.

Classen. R.W.,1963. Vibration of Skew Cantilever Plates, American Institute of Aeronautics and Astronautics Journal, vol.1 pp.1222.

Conway. H.D., and K.A. Farnham., 1965. The Free Flexural Vibrations of Triangular Rhombic and Parallelogram Plates and Some Analogies, International Journal of Mechanical Sciences, vol.7,pp. 811-816.

Durvasula. S., 1969. Natural Frequencies and Modes of Clamped Skew Plates, American Institute of Aeronautics and Astronautics Journal, vol.7, pp.1164-1166.

Garg. A.K., R.K. Khare., and T. Kant., 2006. Free Vibration of Skew Fiber-Reinforced Composite and Sandwich Laminates Using a Shear Deformable Finite Element Model, Journal of Sandwich Structures and Materials, vol.8, pp. 33-53.

Hamada. M.,1959. Compressive or Shearing Buckling Load and Fundamental Frequency of a Rhomboidal Plate with All Edges are Clamped, Bulletin of JSME, vol.2,pp.520-526.

Hasegawa. M., 1957.Vibration of Clamped Parallelogrammic Isotropic Flat Plates, Journal of Aeronautical Sciences, vol.24, pp.145-146.

Jones. R.M.,1975. Mechanics of Composite Materials, McGraw-Hill, New York.

Kamal. K., and Durvasula. S., 1986. Some Studies on Free Vibration of Composite Laminates, Composite Structure, vol.5 pp.177-202.

Kaul.R.M., and V. Cadambe,1956. The Natural Frequencies of Thin Skew Plates, Aeronautical Quarterly, vol.7,pp. 337-352.

Krishnan. A., and Deshpande J.V., 1992. Vibration of Skew Laminates, Journal of Sound and Vibrations, vol.153, No.2, pp. 351358.

Krishna Reedy. A.R., and R. Palaninathan., 1999. Free Vibration of Skew Laminates, Computers and Structures, vol.70, pp. 415423.

Kuttler. J.R., and V.G. Sigillito., 1980. Upper and Lower Bounds for Frequencies of Clamped Rhombical Plates, Journal of Sound and Vibration, vol.68, pp. 597-607.

Laura. P.A., and J. Grosson., 1968. Fundamental Frequency of Vibration of Rhombic Plates, Journal of Acoustical Society of America, vol. 44, pp. 823-824.

Liew. K.M., and K.Y. Lam., 1990. Application of Two- Dimensional Orthogonal Plate Functions to Flexural Vibration of Skew Plates, Journal of Sound and Vibration, vol.132, No.2, pp. 241-252. 
Liew. K.M., and C.M.Wang., 1993. Vibration Studies on Skew Plates: Treatment of Internal Line Supports, Computers and Structures, vol.49, No.6, pp. 941-951.

Malhotra. S.K., N. Ganesan., and M.A. Veluswami., 1988. Effect of Fiber Orientation and Boundary Conditions on The Vibration Behavior of Orthotropic Rhombic Plates, Journal of Composites, vol.19, No.2, pp.127-132.

McGee. O.G., and Butalia. T.S., 1994. Natural Frequencies of Shear Deformable Cantilevered Skew Thick Plates, Journal of Sound and Vibrations, vol.176, pp.351-376.

Mizusawa. T., T. Kajita., and M. Naruoka., 1979. Vibration of Skew Plates by Using B-Spline Functions, Journal of Sound and Vibration, vol.62,pp 301-308.

Mizusawa. T., T. Kajita., and M. Naruoka., 1980. Analysis of Skew Plate Problems with Various Constraints, Journal of Sound and Vibration, vol.68, pp. 575-584.

Mizusawa. T., and T. Kajita., 1986. Vibration and Buckling of Skew Plates with Edges Elastically Restrained Against Rotation, Computers and Structures, vol.22, pp. 987-994.

Mizusawa. T., and T. Kajita., 1987. Vibration of Skew Plates Resting on Point Supports, Journal of Sound and Vibration, vol. 115 , pp. 243-251.

Monforton. G.R., 1968. Finite Element Displacement and Vibration Analysis of Skew Plates, Report18, Division of Solid Mechanics, Structural and Mechanical Design Case, Western Reserve University, Cleveland, Ohio.

Moloy. K. Singha., and M. Ganapathi., 2004. Large Amplitude Free Flexural Vibrations of Laminated Skew Plates, Journal of Non-Linear Mechanics, vol.39, pp.1709-1720.

Nair. P.S., and Durvasula. S., 1973. Vibration of Skew Plates, Journal of Sound and Vibration, vol. 26, No.1,pp.1-19.

Srinivasan. R.S., and S.V. Ramachandran., 1975. Vibration of Generally Orthotropic Skew Plates, Journal of Acoustic Society of America, vol.57, pp.1113-1118.

Singh. B,. and Chakraverthy. S., 1994. Flexural Vibration of Skew Plates Using Boundary Characteristic Orthogonal Polynomials in Two Variables, Journal of Sound and Vibrations, vol.173, pp.157-178.

Thangam Babu. P.V., and D.V. Reddy., 1971. Frequency Analysis of Skew Orthotropic Plates by the Finite Strip Method, Journal of Sound and Vibration, vol.18, No.4, pp.465-474.

\section{Biographical notes}

C.V. Srinivasa received M. Tech. from Visvesvaraya Technological University, Belgaum, India in 2003 by securing III Rank. He is a Assistant Professor in the Department of Mechanical Engineering, GM Institute of Technology, Davangere, Karnataka, India-577006. Presently he is pursuing Ph.D at Research Centre, Department of Mechanical Engineering, J.N.N. College of Engineering, Shivamogga, affiliated to Visvesvaraya Technological University, Karnataka, India. His research interests include stress analysis, finite element method and experimental material characterization. He is a Member of ISTE (India), ISTAM.MRSI.

Dr. Y.J. Suresh is a Professor in the Department of Mechanical Engineering, J.N.N. College of Engineering, Shivamogga, Karnataka, India. He received Ph.D. from Indian Institute of Technology, Madras, India He has more than 30 years of experience in teaching and research. His current area of research includes Design, Stress analysis, finite element analysis, vibration. He has published many papers in referred international journals. He is a Fellow of IE (India), ISTE (India), SEM, AMAeI (Associate Member of Aeronautical Society of India).

W.P. Prema Kumar is a Professor and head in the Department of Civil Engineering, Nagarjuna College of Engineering \& Technology, Bangalore-562110, India. He received Ph.D. from Indian Institute of Technology, Madras, India. He has more than 35 years of experience in teaching and research. His current area of research includes Finite Element Analysis and Laminated Composite Structures. He has published many papers in referred national and international journals. He is a Member of IE (India), ISTE (India), American Society of Civil Engineers (India Section) and Member of Indian Standards.

Received May 2012

Accepted October 2012

Final acceptance in revised form October 2012 